\title{
Lexical Decomposition and Comparative Structures for Japanese Determiners
}

\author{
Takuro Tanaka \\ University of Connecticut
}

\section{Introduction}

This paper is about the interpretation of Japanese ooku-no and takusan-no, which seem to share the same meaning. Both of these items are roughly translated as many in English.
a. John-wa
ooku-no
hon-wo
yon-da
John-Nom
book-Acc
read-Past
b. John-wa
many-Gen
hon-wo
yon-da
John-Nom
many-Gen
book-Acc
read-Past
'John read many books'

In English, many is used in non-comparative constructions, and more is used in comparative constructions as shown in (2). In Japanese, however, ooku-no and takusan-no can be used in both comparatives and non-comparatives, as shown in (3).

(2) a. John read many books

b. John read more books than Mary did.

c. * John read many books than Mary did.
a. John-wa Mary yorimo John-Nom Mary than
ooku-no
hon-wo
yon-da
'John read more books than Mary did.'
b. John-wa Mary yorimo takusan-no hon-wo yon-da John-Nom Mary than many-Gen books-Acc read-Past 'John read more books than Mary did.,'

In the rest of the paper, I will show that the Japanese lexical items ooku-no and takusan-no actually have different meanings and they appear in different

\footnotetext{
For very valuable comments, I am very much grateful to the audiences at UConn Ling Lunch, The annual Southern New England Workshop in Semantics (UConn), SALT16 (The University of Tokyo). Special thanks go to Jonathan Bobaljik, Jon Gajewski, Makoto Kanazawa, Naho Kobayashi, Kimiko Nakanishi, Toshiko Oda, Barbara Partee, Maribel Romero, Uli Sauerland, Yael Sharvit, Reiko Shimamura, William Snyder, Christopher Tancredi, Satoshi Tomioka, and Susi Wurmbrand for their helpful and thought provoking feedback. All errors are of course mine.

${ }^{1}$-no of ooku-no and takusan-no can be omitted. Traditionally, ooku and takusan have been assumed as manner adverbs. We will put aside these variant forms in this paper.
} 
structures. The differences between them are especially clear in three types of comparative sentences: cardinal comparative (0), proportional comparative (0), and differential comparative (0). I argue that roughly, the difference between ooku-no and takusan-no is this: ooku-no always appears in comparative constructions, even when the meaning is non-comparative, and takusan-no always requires a relatively large degree. To capture this difference, I rely on previous analyses of 'many' and of comparative constructions. In particular, I suggest that there is a proportional d-many which appears in constructions with a proportional reading, akin to the cardinal d-many which has been suggested in the literature.

\section{Data}

In some particular situations, ooku-no and takusan-no in comparative sentences give rise to different interpretations. We will look at the data showing the differences one by one.

\subsection{Cardinal Comparatives}

First, consider the situation described in (4). This is a list of the numbers of students who receive financial aid (FA, henceforth) in 6 universities. For example, 111 students receive financial aid in University A, 92 in University B, and so on.

\section{(4) Situation A-1}

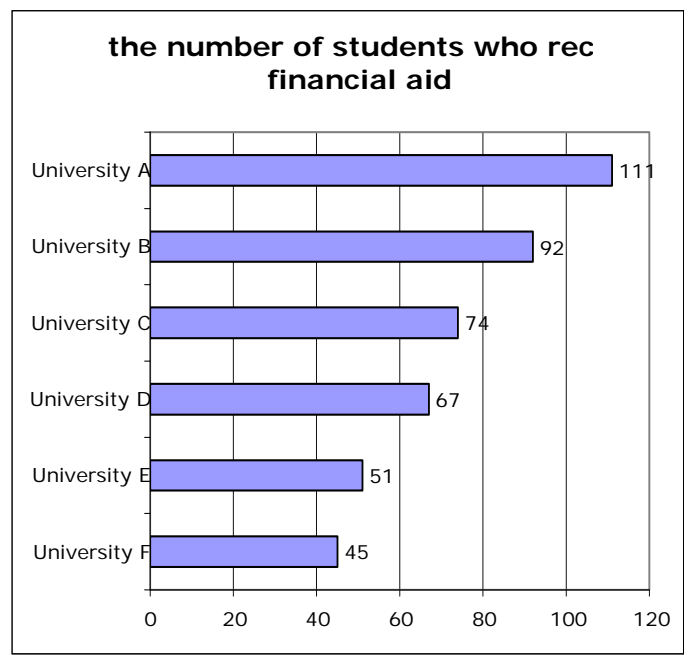

Given this situation, the salient interpretation of (5) is the following: the number of students with financial aid in University A, 111, can be perceived as "large," but the number of such students in University F, 45, cannot ${ }^{2}$. Here both ooku-no and takusan-no give rise to the same judgment in the same situation in noncomparative "many P Q" configurations. This judgment relies on the numbers of students with financial aid in the universities. This reading is called the cardinal reading (Barwise and Cooper 1981, Partee 1988, a.o.)

\footnotetext{
${ }^{2}$ See Tanaka (2005) for discussion of the contextual factors that influence salience.
} 
(5)
a. A daigaku dewa
ooku-no
gakusei-ga
FA-wo
moratteiru Univ. A in
many-Gen
students-Nom FA-Acc
receive
b. A daigaku de-wa
FA-wo
moratteiru Univ. A in many-Gen students-Nom FA-Acc receive 'In University A, many students receive financial aid'
a. \#F daigaku dewa
ooku-no
gakusei-ga FA-wo
moratteiru
Univ. $F$ in
many-Gen
students-Nom FA-Acc
receive
b. \#F daigaku de-wa
takusan-no
gakusei-ga
FA-wo
moratteiru
Univ. $\mathrm{F}$ in
many-Gen
students-Nom FA-Acc receive
'In University F, many students receive financial aid'

In comparative sentences, however, these two items give rise to different truth conditions. Under situation A-1 in (4) above where the difference between the number of students with financial aid in University E (51) and the one in University F (45) is relatively small (just 6), ooku-no is available for the comparative sentence in (7a), but takusan-no is not available for the one in (7b).

(7) Cardinal comparative

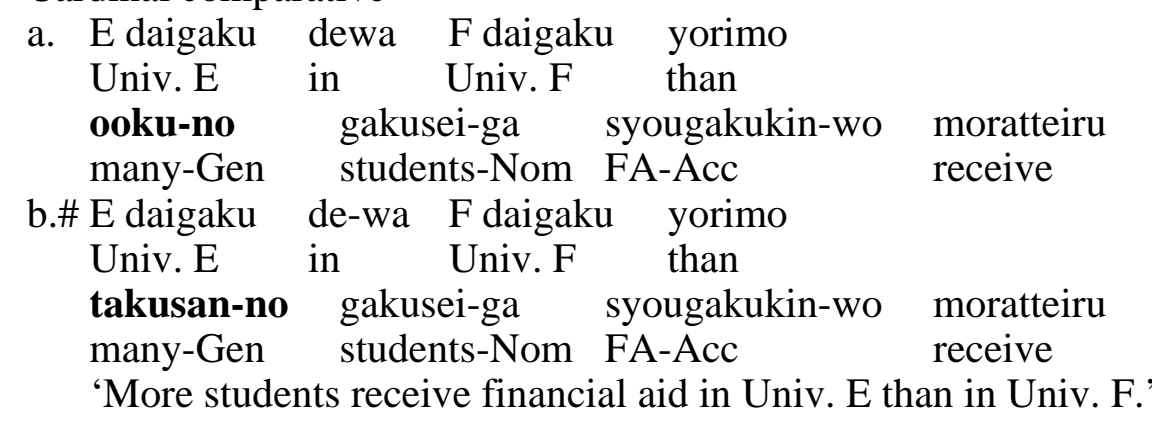

Consider other situations where the comparative sentences in (7) are judged. The judgments are represented as the table in (9).

\section{(8) a. Situation A-2}

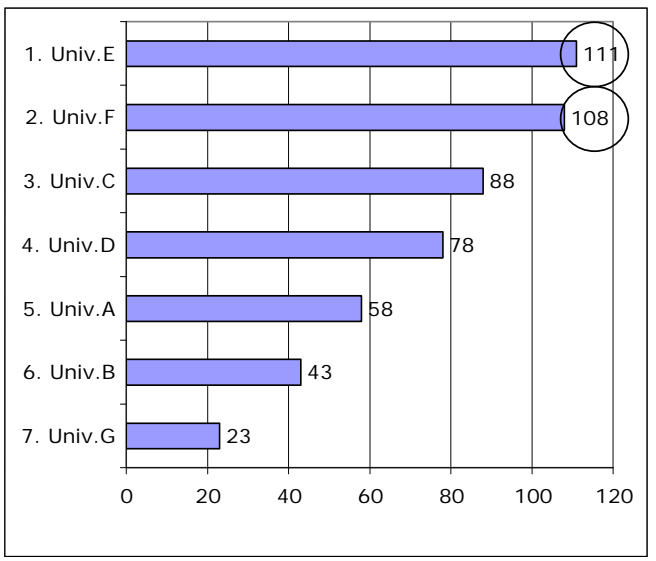

b. Situation A-3

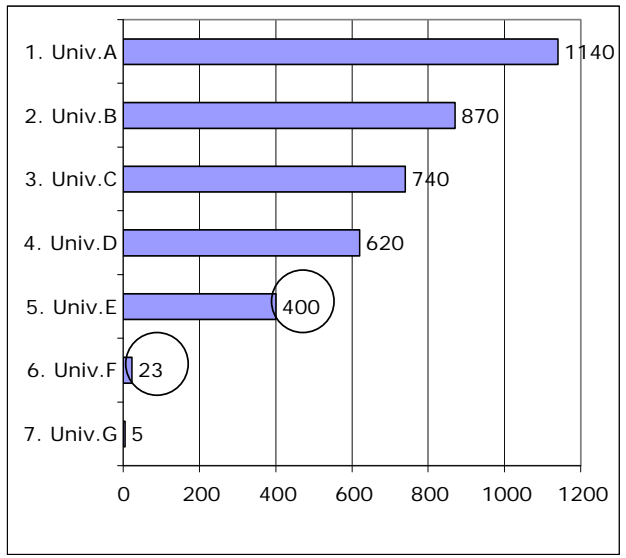


(9) Judgments of the comparatives in (7) under situations A-1, A-2, and A-3

\begin{tabular}{|l|c|c|c|}
\hline & Situation A-1 & Situation A-2 & Situation A-3 \\
\hline (11a) with ooku-no & $\checkmark$ & $\checkmark$ & $\checkmark$ \\
\hline (11b) with takusan-no & $\#$ & $\#$ & $\checkmark$ \\
\hline
\end{tabular}

A comparative sentence with takusan-no is allowed only in situation A-3 in (8) where the difference between the two relevant numbers is "large.” To explain this, we tentatively assume (10) as the condition on the acceptability of takusan-no in cardinal comparatives.

(10) Cardinal comparatives with takusan-no require that the difference of two compared numbers be "large" in a given context.

What we should do is explain where (10) comes from.

\subsection{Proportional Comparatives}

The English determiner many has another reading: the proportional reading (Partee (1988), de Hoop (1996), a.o.), and Japanese ooku-no and takusan-no have it as well. To consider this reading, think of the situation in (11). In this situation, 51 students in University E receive financial aid, but this is a big university with no less than 350 students. The percentage of students with financial aid is just $15 \%$. On the other had, 45 students receive financial aid in University F, but this university is small with only 52 students. The percentage of students with financial aid is $90 \%$ in this university.

Situation B

a. University E: $\frac{\mid \text { students with financial aid } \mid}{\mid \text { total number of students } \mid}=\frac{51}{350} \cong 15 \%$

\begin{tabular}{ll|l|}
\hline & & \\
$0 \%$ & $15 \%(51)$ & $100 \%$ (350)
\end{tabular}

b. University F: $\frac{\mid \text { students with financial aid } \mid}{\mid \text { total number of students } \mid}=\frac{45}{52} \cong 90 \%$

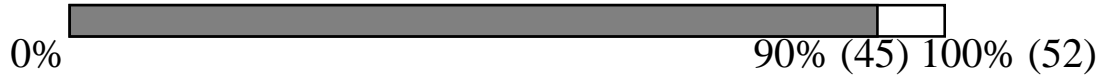

Given this situation, University E does not seem to have a large proportion of students with financial aid in (12), but the proportion in University $\mathrm{F}$ is judged as "large" in (13).
a. \#E daigaku dewa
ooku-no
gakusei-ga
FA-wo moratteiru
Univ. E in
many-Gen
students-Nom
FA-Acc receive
b \#E daigaku dewa
takusan-no
gakusei-ga
FA-wo moratteiru
Univ. E in
many-Gen
students-Nom FA-Acc receive
'In University E, many students receive financial aid' 

a. F daigaku dewa
ooku-no
gakusei-ga
FA-wo moratteiru
Univ. $\mathrm{F}$ in
many-Gen
students-Nom
FA-Acc receive
b. F daigaku dewa
Univ. F in
takusan-no
gakusei-ga
FA-wo moratteiru
'In University F, many students
students-Nom FA-Acc receive

Pay attention to the fact that the judgments are the other way around in (6) and (13) even though the number of students with financial aid is the same. Judgments for (6) are based on a cardinal reading; the crucial thing here is the number of students with financial aid, 45. For the judgment of (13), however, the proportion of students with financial aid, 90\%, is relevant. The contrast between (12) and (13) shows that both ooku-no and takusan-no permit a proportional reading.

However, only takusan-no allows comparative sentences with a proportional reading. To compare the two proportions in University E (15\%) and University F (90\%) under the situation in (11), a proportional comparative with takusan-no can be used, but not with ooku-no. (14a) itself is grammatical, but it provides only a cardinal reading, not a proportional one.

Proportional comparative
a. \#F daigaku dewa E daigaku yorimo
Univ. $\mathrm{F}$ in Univ. $\mathrm{E}$ than
ooku-no gakusei-ga syougakukin-wo moratteiru
many-Gen students-Nom FA-Acc receive
b. F daigaku de-wa E daigaku yorimo
Univ. $\mathrm{F}$ in Univ. E than
takusan-no gakusei-ga syougakukin-wo moratteiru
many-Gen students-Nom FA-Acc receive
'More students receive financial aid in Univ. $F$ than in Univ. E.'

\subsection{Differential Comparatives}

Next, we will look at data with differential comparatives. The typical example of a differential comparative is (15), which mentions that the difference of tallness of John and Mary is one inch.

\section{(15) John is one inch taller than Mary}

There are two types of differential comparatives with respect to the distinction between cardinal and proportional readings. In cardinal differential constructions, only ooku-no is allowed. Let us take situation B in (11), where the difference between University $\mathrm{E}$ and $\mathrm{F}$ is 6.

$$
\begin{aligned}
& \text { a. E daigaku dewa F daigaku yorimo } \\
& \text { Univ. } \mathrm{E} \text { in Univ. } \mathrm{F} \text { than } \\
& \text { 6-nin ooku-no gakusei-ga syougakukin-wo moratteiru } \\
& \text { 6-CL many-Gen students-Nom FA-Acc receive } \\
& \text { b.* E daigaku dewa } \mathrm{F} \text { daigaku yorimo } \\
& \text { Univ. E in Univ. F than } \\
& \text { 6-nin takusan-no gakusei-ga syougakukin-wo moratteiru } \\
& \text { 6-CL many-Gen students-Nom FA-Acc receive } \\
& \text { '6 more students receive financial aid in Univ. E than in Univ. F.' }
\end{aligned}
$$


As for proportional differential constructions, on the other hand, neither ooku-no nor takusan-no are allowed.

$$
\begin{aligned}
& \text { a. \#F daigaku dewa E daigaku yorimo } \\
& \text { Univ. } \mathrm{F} \text { in Univ. } \mathrm{E} \text { than } \\
& \text { 75\% ooku-no gakusei-ga syougakukin-wo moratteiru } \\
& 75 \% \text { many-Gen students-Nom FA-Acc receive } \\
& \text { b. }{ }^{*} \text { F daigaku dewa E daigaku yorimo } \\
& \text { Univ. } \mathrm{F} \text { in Univ. } \mathrm{E} \text { than } \\
& \mathbf{7 5 \%} \text { takusan-no gakusei-ga syougakukin-wo moratteiru } \\
& 75 \% \text { many-Gen students-Nom FA-Acc receive } \\
& \text { 'The percentage of students with financial aid in University } \mathrm{F} \text { is } 75 \% \\
& \text { larger than the one in University E' }
\end{aligned}
$$

(17a) is not ungrammatical, but it does not describe situation B in (11); it means that the number of students with financial aid in University $F$ is larger than the one in University E by $75 \%$ of 51 ( $\approx 39)$. In short, (17a) means that " 90 students receive financial aid in University $F$." This is not the intended reading. The proportional differential comparative construction here compares the two proportions, $15 \%$ and $90 \%$.

Following the judgments of (7a), (14a), (16a), and (17a), let us assume (18) as the condition on the acceptability of ooku-no.

(18) In comparative sentences, ooku-no is compatible with a cardinal comparative interpretation, but not with a proportional comparative interpretation.

Based on our three types of observations represented above, we will investigate the following questions about the difference between ooku-no and takusan-no.

a. Why does (7b) with takusan-no sound odd in situation A-1 in (4)?, i.e., why does a comparative sentence with takusan-no require the difference of two compared numbers to be "large" (the condition in $(10))$ ?

b. Why cannot (14a) with ooku-no describe situation B in (11)?, i.e., why does ooku-no prohibit a proportional comparative reading (the condition in (18))?

c. Why does ooku-no permit cardinal differential comparatives, but takusan-no does not ((16))? Why is it the case that both of them do not allow proportional differential comparatives ((17))?

\section{Theoretical Background}

In this section, we will review the theoretical background needed to answer the questions in (19). Mainly, we will see previous treatments of comparative construction, and of the determiner many in English. 


\subsection{Comparative constructions}

It has been suggested in the literature that there are two types of comparative constructions: non-differential comparative and differential comparative (cf. von Stechow 1984, Rullmann 1995, Hackl 2000, Heim 2000, Nakanishi 2004, among many others). Depending on the type of comparative, two types of comparative morphemes - er have been suggested. Let us call the non-differential comparative $-e r_{1}$, and differential comparative $-e r_{2}$.

\subsection{Non-differential Comparative: $-e_{1}$}

The denotation of the comparative morpheme for ordinary comparatives is (20). The maximality in the denotation is defined as (21).

(20) $\llbracket-e r_{1} \rrbracket:=\lambda D^{\prime}{ }_{d t} \lambda D_{d t} \cdot \max (\mathrm{D})>\max \left(\mathrm{D}^{\prime}\right)$

(21) $\max (\mathrm{D})=\imath \mathrm{d}$. $\mathrm{D}(\mathrm{d})=1 \wedge \forall \mathrm{d}^{\prime}\left[\mathrm{D}\left(\mathrm{d}^{\prime}\right)=1 \rightarrow \mathrm{d}^{\prime} \leq \mathrm{d}\right]$

(Heim 2000)

Based on this semantics, the truth conditions of the comparative sentence in (22) are given in (22b), following the LF in (23).

(22) a. John is taller than six feet

b. $\max \{\mathrm{d}: \operatorname{tall}(\mathrm{j}, \mathrm{d})\}>6$,

LF of (22a)

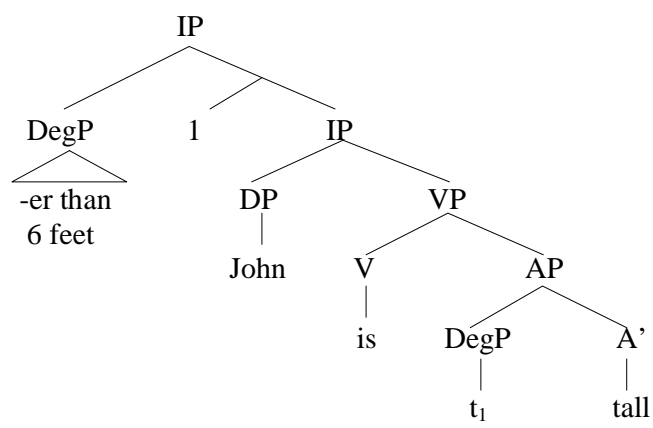

\subsubsection{Differential comparative: $-e_{2}$}

In addition to non-differential comparatives such as (22a), there is another type of comparative sentence: differential comparative. (24) is a typical example of a differential comparative.

(24) John is one inch taller than Mary

The comparative morpheme $-e r_{1}$, which we have already seen in (20), cannot describe the appropriate truth conditions for the sentence because it does not contain the argument slot for the difference of two degrees, one inch. We need another comparative morpheme for differential comparatives, which is formalized in (25).

$$
\llbracket-e r_{2} \rrbracket:=\lambda \mathrm{D}^{\prime}{ }_{\mathrm{dt}} \lambda \mathrm{d}_{\mathrm{d}} \lambda \mathrm{D}_{\mathrm{dt}} \cdot \max (\mathrm{D})-\max \left(\mathrm{D}^{\prime}\right)=\mathrm{d}
$$


Based on this comparative morpheme, the LF and truth condition of (24) would be (26) and (27), respectively.

LF of (24)

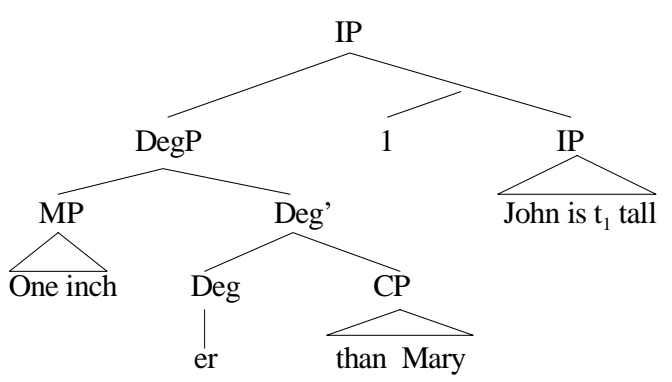

$\max \{\mathrm{d}: \operatorname{tall}(\mathrm{j}, \mathrm{d})\}-\max \{\mathrm{d}: \operatorname{tall}(\mathrm{m}, \mathrm{d})\}=1 ”$

\subsection{Determiner many}

Regarding the semantics of many, several kinds of analyses have been suggested. In these analyses, we will see two types of semantics of many: the traditional determiner many whose type is <et, <et, $\mathrm{t}>>$, and the comparative abstract d-many whose type is $<\mathrm{d}$, $<\mathrm{et},<\mathrm{et}, \mathrm{t}>>>$. Let us call the former many ${ }_{1}$, and the latter many $_{2}$. The determiner many $y_{1}$ further has two types of variants: cardinal reading many $_{1 \mathrm{C}}$ and proportional reading many ${ }_{1 \mathrm{P}}$.

\subsection{1. many $_{1}$ : the traditional determiner of $<e t,<e t, t>>$ type}

Barwise and Cooper (1981) argue that the type of natural language determiners, for example, every, no, or some, is <et, <et, $\mathrm{t}>>$.
a. $\llbracket$ every $\rrbracket=\left[\lambda \mathrm{p}_{\mathrm{et}} \lambda \mathrm{q}_{\mathrm{et}} \cdot \mathrm{p} \subseteq \mathrm{q}\right]$
b. $\llbracket$ no $\rrbracket=\left[\lambda p_{\mathrm{et}} \lambda \mathrm{q}_{\mathrm{et}} \cdot \mathrm{p} \cap \mathrm{q}=\varnothing\right]$
c. $\llbracket$ some $\rrbracket=\left[\lambda p_{\mathrm{et}} \lambda q_{\mathrm{et}} \cdot \mathrm{p} \cap \mathrm{q} \neq \varnothing\right]$

They argue that the determiner many has the same type even though the interpretation of many is slightly different from the one of other determiners in (28), in that its truth conditions depend on the conversational background.

(29) 【 many $_{1 \text {-Cardinal }} \rrbracket=\left[\lambda \mathrm{p}_{\mathrm{et}} \lambda \mathrm{q}_{\mathrm{et}}|\mathrm{p} \cap \mathrm{q}|>\rho\right.$, where $\rho$ is a "large” number $]$

(30) a. Many linguists are lazy

b. $\mid\{\mathrm{x}: \mathrm{x}$ is a linguist $\} \cap\{\mathrm{x}: \mathrm{x}$ is lazy $\} \mid$ is "large"

The interpretation of (30a) with many in (29) is based on the number of lazy linguists. This many for the cardinal reading has been discussed in the literature (Barwise and Cooper 1981, Partee 1988, de Hoop and Solà. 1996, a.o.).

It has been said that many has another reading: proportional reading (Partee 1988, Cohen 2001, among many others). In this reading, the number of 
individuals is not relevant to the interpretation, but it is crucial that the proportion of individuals who satisfy the property described with the predicate out of total number of individual be large. The denotation of proportional many is represented as (31).

$$
\llbracket \text { many }_{1 \text {-Proportional }} \rrbracket=\left[\lambda \mathrm{pet}_{\mathrm{et}} \lambda \mathrm{q}_{\mathrm{et} \cdot} \frac{|\mathrm{p} \cap \mathrm{q}|}{|\mathrm{p}|}>\rho \text {, where } \rho \text { is “large” }\right]
$$

Here let us suppose that there are 1000 linguists, and 800 are lazy linguists. Whether 800 is large or not is decided by the context in the cardinal reading. In the proportional reading, however, the number 800 itself does not matter; the proportion of $80 \%$ is relevant to the truth conditions. The proportion of $80 \%$ can be seen as a "large" proportion, rendering (30a) true in the context. Hence, (30a) would be true even in a situation where there are only 20 lazy linguists, if the total number of linguists were just 22, for example.

\subsection{2. many2: $_{2}$ the comparative $d$-many of $<d$, $<e t$, $<e t, t>>>$ type}

Different from many, another type of many has been suggested: comparative dmany. In a comparative construction like (32a), the interpretation is paraphrased as (32b).
a. John is taller than 6 feet
b. There is a degree $\mathrm{d}$ st. John is tall to that degree and $\mathrm{d}$ is greater than $6 \mathrm{ft}$.
c. [-er than 6 feet $]_{1}$ [John is $\mathrm{d}_{1}$-tall]

According to the paraphrase, there are three essential pieces to comparative constructions: a gradable predicate, an expression referring to a degree that provides the standard of comparison, and a comparative relation. The paraphrased interpretation in (32b) means that an integral part of comparatives is a quantifier that ranges over degrees. This degree quantifier is base-generated in the degree argument position of the gradable predicate, and moves up to a clausal node to yield an interpretable structure as shown in (32c) (cf. Heim 2000. We will see the details of comparative constructions later on).

Hackl (2000) extends the analysis to the interpretation of sentences with more. Based on the assumption that more is lexically decomposed into many and er (cf. Ross 1967, Bresnan 1973), Hackl argues that the denotation of comparative d-many is represented as (33), and a sentence in (34a) is paraphrased as (34b). The LF of (34a) would be (35).

$$
\llbracket \text { many }_{2} \rrbracket=\lambda \mathrm{d} \lambda \mathrm{P} \lambda \mathrm{Q} . \exists \mathrm{x}[|\mathrm{x}|=\mathrm{d} \wedge \mathrm{P}(\mathrm{x}) \wedge \mathrm{Q}(\mathrm{x})]
$$

(34) a. More than six boys danced.

b. The maximal degree $d$ st. d-many boys danced exceeds six. 
(35) LF of (34a).

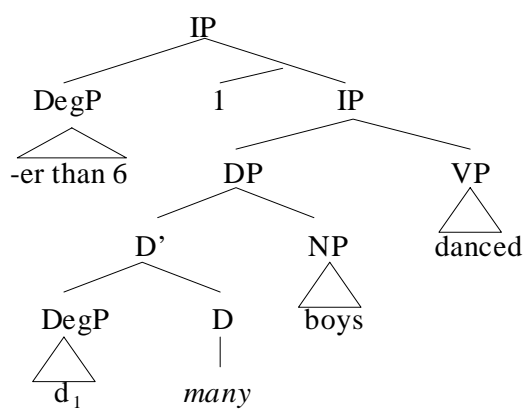

Based on the analysis, the truth conditions of (34a) are: $\max \{\mathrm{d}: \exists y[* \operatorname{boy}(\mathrm{y}) \wedge$ $|\mathrm{y}|=\mathrm{d} \wedge *$ dance $(\mathrm{y})]\}>6$.

What has to be noticed is that comparative d-many in the previous literature appears only in the cardinal reading. There is no reason to assume that it has no proportional counterpart. I suggest that there is a proportional d-many which can be represented as in (36), which we will call many $2 \mathrm{p}$.

$$
\llbracket \text { many }_{2 \mathrm{P}} \rrbracket:=\lambda \mathrm{d} \lambda \mathrm{P} \lambda \mathrm{Q} \cdot \frac{|\mathrm{P} \cap \mathrm{Q}|}{|\mathrm{P}|}=\mathrm{d}
$$

(Proportional d-many)

Let us think about the sentence in (37), for example. The LF and interpretation of the sentence is represented in (38) with many 2 . In this case, the degree argument is not for a cardinal number, but a proportion of dancing boys out of total boys in question.

More than $15 \%$ of the boys danced.
a. LF of (37)
b. Truth condition of (37)

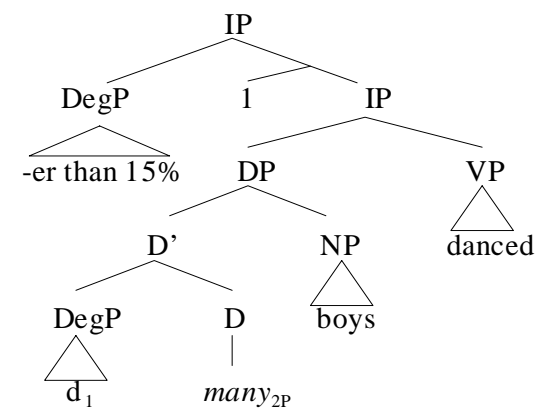

$$
\begin{aligned}
& \mathbb{U}(38 \mathrm{a}) \mathbb{\|}=1 \text { iff } \\
& \max \left\{\mathrm{d}: \frac{|\{\mathrm{x}: \operatorname{boy}(\mathrm{x})\} \cap\{\mathrm{x}: \operatorname{dance}(\mathrm{x})\}|}{|\{\mathrm{x}: \operatorname{boy}(\mathrm{x})\}|}=\mathrm{d}\right\}>15 \%
\end{aligned}
$$

'The maximal degree of proportion of dancing boys exceeds 15\%’

\subsection{Covert degree morpheme LARGE}

A degree morpheme plays an important role for comparative d-many (i.e., many 2 in our terminology). A cardinal number or proportion would be the argument for 
degree. In addition, I suggest that there is a default degree morpheme LARGE, which is phonologically covert ${ }^{3}$.

$$
\llbracket L A R G E \rrbracket^{\mathrm{C}, \mathrm{g}}:=\lambda \mathrm{d} . \mathrm{d} \text { is "large" in C }
$$

This covert degree morpheme satisfies the condition in (10); cardinal comparatives with takusan-no require that the difference of two compared numbers should be "large" in a given context.

\section{Proposal}

In this section I describe my proposal for Japanese ooku-no and takusan-no using the analyses of abstract many and of comparative constructions. The basic assumption is that Japanese ooku-no and takusan-no can be lexically decomposed in several ways, depending on the construction. These two items are not single lexical items, but they consist of some lexical components. The difference between ooku-no and takusan-no lies in which items compose them, and how they combine with each other.

The following are the building blocks to compose Japanese determiners ooku-no and takusan-no.

\section{many}

a. $\llbracket$ many $_{1 \mathrm{C}} \rrbracket:=\lambda \mathrm{P} \lambda \mathrm{Q} .|\mathrm{P} \cap \mathrm{Q}|$ is "large” (cardinal)

b. 【 many $_{1 \mathrm{P}} \rrbracket:=\lambda \mathrm{P} \lambda \mathrm{Q}$. $|\mathrm{p} \cap \mathrm{q}|$ is "large" (proportional)

c. $\llbracket$ many $_{2 \mathrm{C}} \rrbracket:=\lambda \mathrm{d} \lambda \mathrm{P} \lambda \mathrm{Q} \cdot|\mathrm{P} \cap \mathrm{Q}|=\mathrm{d} \quad$ (Comparative cardinal)

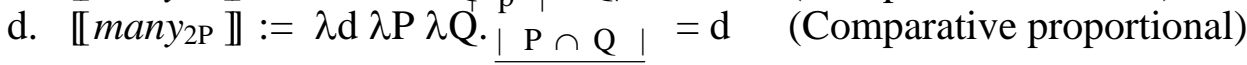
$-e r$
a. $\llbracket-e r_{1} \rrbracket:=\lambda \mathrm{D}_{\mathrm{dt}} \lambda \mathrm{D}_{\mathrm{dt}} \cdot \max (\mathrm{D})>\max \left(\mathrm{D}^{\prime}\right) \quad$ (Non-differential)

b. $\llbracket-e r_{2} \rrbracket:=\lambda \mathrm{D}^{\prime}{ }_{\mathrm{dt}} \lambda \mathrm{d}_{\mathrm{d}} \lambda \mathrm{D}_{\mathrm{dt}}$. $\max (\mathrm{D})-\max \left(\mathrm{D}^{\prime}\right)=\mathrm{d} \quad$ (Differential)

\section{LARGE \\ $\llbracket L A R G E \rrbracket^{\mathrm{C}, \mathrm{g}}:=\lambda \mathrm{d}$. $\mathrm{d}$ is "large" in $\mathrm{C}$}

Ooku-no and takusan-no consist of these elements. Here let us suppose that their lexical decompositions should follow the principles in (43).

(43) a. Ooku-no has to appear in a cardinal comparative structure even in noncomparative sentences. (i.e., only many ${ }_{2 \mathrm{C}}$ in (40c) is available for ooku-no).

b. Takusan-no has to take the default degree morpheme LARGE in any case.

\footnotetext{
${ }^{3}$ Measure phrases can be interpreted either as a degree argument or as a set of degrees (Hackl, 2000)

(i) $\llbracket$ six feet $\rrbracket:=6$,

(ii) $\llbracket$ six feet $\rrbracket:=\lambda$ d. $d=6$,

$\left\{d: d=6^{\prime}\right\}$ is a singleton $\left\{6^{\prime}\right\}$, hence $\max \left\{d: d=6^{\prime}\right\}$ is equal to $6^{\prime}$
} 
(43a) implies that the LF of a non-comparative sentence with ooku-no ((5a), for example) is a comparative structure. (43b) is for the effect of (10): takusan-no requires that the difference of two compared numbers should be "large" in a given context.

The lexical decomposition of ooku-no and takusan-no varies depending on the structures they appear in. Their decompositions are represented as follows.

(44) Lexical decomposition of ooku-no and takusan-no.

\begin{tabular}{|l|c|c|}
\hline & Ooku-no & Takusan-no \\
\hline (a) Cardinal Non-Comparative & Many $_{2 C}+L A R G E+-\mathrm{er}_{1}$ & $\mathrm{Many}_{2 \mathrm{C}}+\mathbf{L A R G E}$ \\
\hline (b) Cardinal Comparative & Many $_{2 \mathrm{C}}+-\mathrm{er}_{1}$ & $\mathrm{Many}_{2 \mathrm{C}}+\mathbf{L A R G E}+-\mathrm{er}_{2}$ \\
\hline (c) Cardinal Differential Comparative & Many $_{2 \mathrm{C}}+(\mathrm{numeral})+-\mathrm{er}_{2}$ & $*$ \\
\hline (d) Proportional Non-Comparative & Many $_{2 \mathrm{C}}+L A R G E+-\mathrm{er}_{1}$ & $\mathrm{Many}_{2 \mathrm{P}}+\mathbf{L A R G E}$ \\
\hline (e) Proportional Comparative & $*$ & $\mathrm{Many}_{2 \mathrm{P}}+\mathbf{L A R G E}+-\mathrm{er}_{2}$ \\
\hline (f) Proportional Differential Comparative & $*$ & $*$ \\
\hline
\end{tabular}

All lexical decomposing involves many ${ }_{2 \mathrm{C}}$, which means that many $_{1}(<\mathrm{et},<\mathrm{et}, \mathrm{t}>>$ type) is not available in Japanese ooku-no and takusan-no. The table reveals that ooku-no always appears in a comparative construction, lexically decomposed into many $_{2 \mathrm{C}}$ and -er, and comparative sentences with takusan-no are always differential comparatives with $L A R G E$ and $-e r_{2}$. We will see the specific implementation of these lexical decompositions in the next section, and answer the questions posed in (19).

\section{Implementations}

\subsection{Cardinal Non-Comparatives}

First, we will look at non-comparative sentences under a cardinal reading as in (45) $(=(5))$. In situation A-1 in (4), both sentences are judged as true. Their LFs and interpretations are given in (46).

a. A daigaku dewa ooku-no gakusei-ga FA-wo moratteiru Univ. A in many-Gen students-Nom FA-Acc receive

b. A daigaku de-wa takusan-no gakusei-ga FA-wo moratteiru Univ. A in many-Gen students-Nom FA-Acc receive "In University A, many students receive financial aid"
a. ooku-no ((45a))
b. takusan-no ((45b))
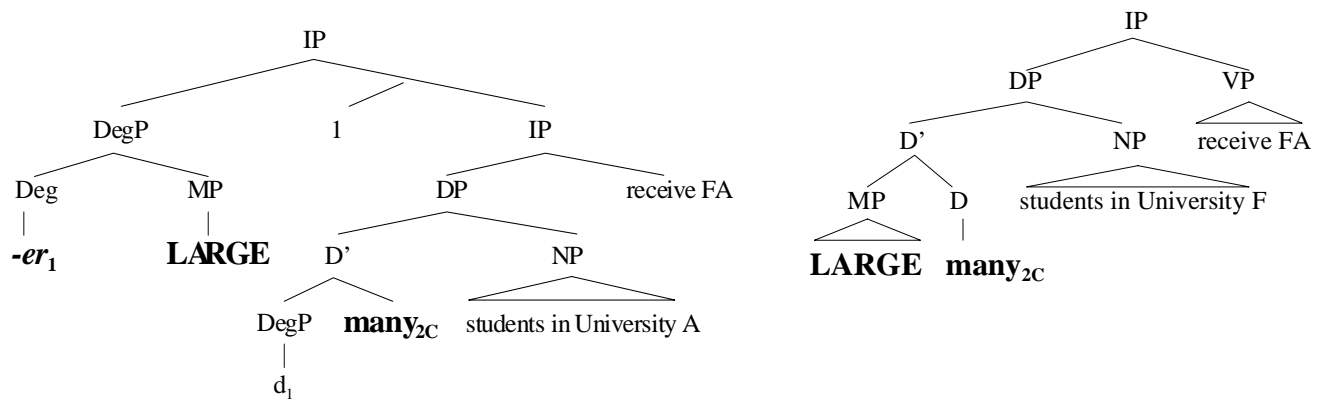

LARGE $\operatorname{many}_{2 \mathrm{C}}$ 
$\llbracket(46 \mathrm{a}) \rrbracket=1$ iff $\max \{\mathrm{d}: \mathrm{d}=\mid\{\mathrm{x}: \mathrm{x}$ is a stdt with FA in Univ.A $\} \mid\}>$ "large"

$\llbracket(46 b) \rrbracket=1$ iff $\mid\{x: x$ is a stdt with FA in Univ.A $\} \mid$ is "large”

Following (43a), ooku-no always requires the comparative construction. (45a) is a non-comparative sentence, but its construction should be a comparative one. The interpretation is that the number of students who receive financial aid in University A, 111, is larger than the "large" number in this situation (4).

\subsection{Cardinal Comparatives}

Next let us look at cardinal comparative sentences in $(47)(=(7))$ in the situation in (4). Remember ooku-no is compatible with the situation, but (47b) with takusanno is judged as false. They address our first question in (19a): why does a comparative sentence witih takusan-no require the difference of two compared numbers to be "large"?

Their LF and interpretations are shown in (48), following (43).

a. E daigaku dewa $\mathrm{F}$ daigaku yorimo

Univ. $\mathrm{E}$ in Univ. $\mathrm{F}$ than

ooku-no gakusei-ga syougakukin-wo moratteiru many-Gen students-Nom FA-Acc receive

b.\# E daigaku de-wa $\mathrm{F}$ daigaku yorimo Univ. $\mathrm{E}$ in Univ. $\mathrm{F}$ than

takusan-no gakusei-ga syougakukin-wo moratteiru many-Gen students-Nom FA-Acc receive 'More students receive financial aid in Univ. E than in Univ. F.'

(48)

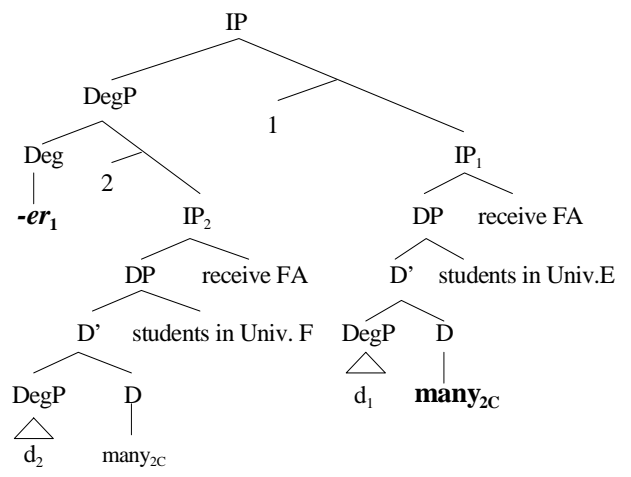

b. takusan-no ((47b))

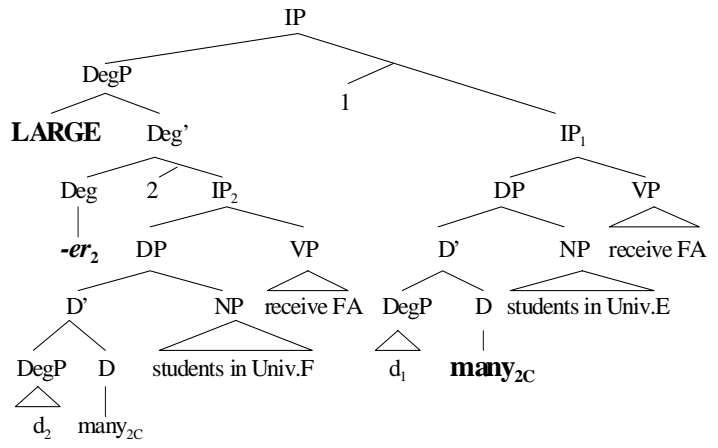

$\llbracket(48 a) \rrbracket=1$ iff $\max \{\mathrm{d}: \mathrm{d}=\mid\{\mathrm{x}: \mathrm{x}$ is a stdt with FA in Univ.E $\} \mid\}>$ $\max \{\mathrm{d}: \mathrm{d}=\mid\{\mathrm{x}: \mathrm{x}$ is a stdt with FA in Univ.F $\} \mid\}$

$\llbracket(48 b) \rrbracket=1$ iff $\max \{\mathrm{d}: \mathrm{d}=\mid\{\mathrm{x}: \mathrm{x}$ is a stdt with FA in Univ.E $\} \mid\}-$ $\max \{\mathrm{d}: \mathrm{d}=\mid\{\mathrm{x}: \mathrm{x}$ is a stdt with FA in Univ.F $\} \mid\}=$ 'large'

In the case of ooku-no, the truth conditions are given straightforwardly: the umber of students with financial aid in University $\mathrm{E}$ is larger than the one in University F. Based on the restriction in (43b), however, a comparative construction with takusan-no should always be a differential comparative, and the difference should 
be 'large' because of the default degree morpheme LARGE. This is not satisfied in the situation in (4), where the difference between the two universities is not relatively 'large.'

\subsection{Cardinal Differential Comparatives}

Next are the cardinal differential comparatives in $(49)(=(16))$ in the situation in (4). Takusan-no gives rise to an unacceptable, which is relevant to our question of (19c): why does ooku-no permit cardinal differential comparatives, but takusanno does not?
a. E daigaku dewa
Univ. E in
F daigaku yorimo
Univ. F than
6-nin ooku-no gakusei-ga
syougakukin-wo 6-CL many-Gen students-Nom FA-Acc
moratteiru
b.* E daigaku dewa
F daigaku yorimo
Univ. E
in
Univ. F
than
6-nin takusan-no gakusei-ga syougakukin-wo moratteiru 6-CL many-Gen students-Nom FA-Acc receive ' 6 more students receive financial aid in Univ. E than in Univ. F.'
a. Ooku-no ((49a))
b. *Takusan-no ((49b))

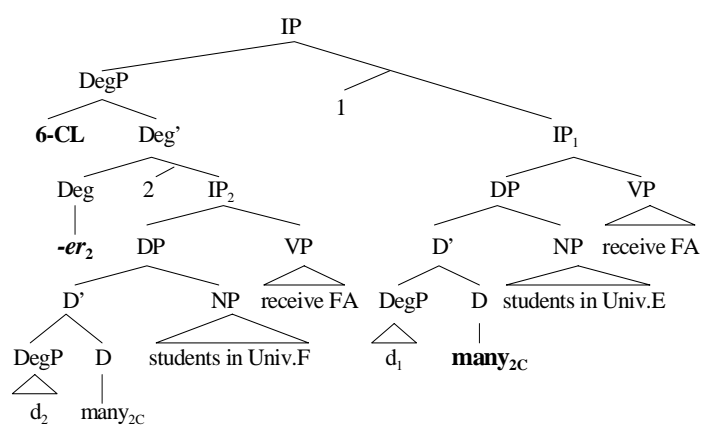

The default morpheme LARGE and a numeral degree morpheme conflict

$\llbracket(50 \mathrm{a}) \rrbracket=1$ iff $\max \{\mathrm{d}: \mathrm{d}=\mid\{\mathrm{x}: \mathrm{x}$ is a stdt with FA in Univ.E $\} \mid\}-$
$\max \{\mathrm{d}: \mathrm{d}=\mid\{\mathrm{x}: \mathrm{x}$ is a stdt with FA in Univ.F $\} \mid\}=6$

In the case of ooku-no, $-e r_{2}$ takes the degree morpheme ' 6 ' as its argument to describe the difference between the two universities. Takusan-no, however, should take the default degree morpheme $L A R G E$, and it cannot take any more degree morphemes. These two degree morphemes compete for the same slot in the tree. This is the answer to one of our questions in (19c).

\subsection{Proportional Non-Comparatives}

Now let us turn to the proportional reading. $(51 \mathrm{a}, \mathrm{b})(=(13))$ are examples of proportional non-comparative sentences under the situation in (11), where the proportion in University $\mathrm{F}$ is $90 \%$, which is regarded as 'large.' 

a. F daigaku dewa ooku-no
gakusei-ga FA-wo moratteiru Univer. $\mathrm{F}$ in many-Gen students-Nom FA-Acc receive
b. F daigaku dewa takusan-no gakusei-ga FA-wo moratteiru Univ. $\mathrm{F}$ in many-Gen students-Nom FA-Acc receive 'In University F, many students receive financial aid'

Following the restriction in (43) and the decomposition options in (44), ooku-no cannot involve the proportional many $\mathrm{p}_{\mathrm{P}}$, and the proportional reading should be given indirectly ${ }^{4}$. The structure of (51a) is comparative, even though the sentence is non-comparative. The number of students with FA is compared with the 'large' number in the given context. On the other hand, takusan-no can consist of many ${ }_{\mathrm{P}}$ for the proportional reading, and the proportional reading is available.

a. ooku-no ((51a))

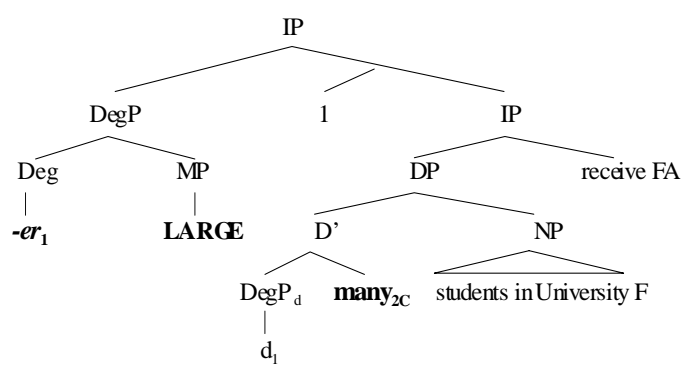

b. takusan-no ((51b))

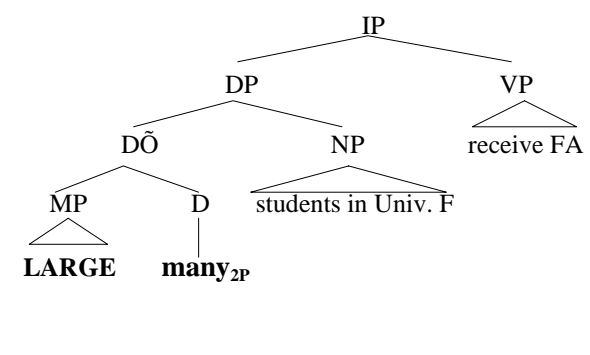

$\llbracket(52 a) \rrbracket=1$ iff $\max \{\mathrm{d}: \mathrm{d}=\mid\{\mathrm{x}: \mathrm{x}$ is a stdt with FA in Univ.F $\mid\}>$ "large"

$\llbracket(52 b) \rrbracket=1$ iff $\frac{\mid\{x: x \text { is a stdt with FA in Univ.F }\} \mid}{\mid\{x: x \text { is a stdt in Univ. }\} \mid}$ is "large"

\subsection{Proportional Comparatives}

Our question in (19b) was about proportional comparatives: ooku-no is not compatible with proportional comparatives.

(53) Proportional reading under the situation in (11)
a.\# F daigaku dewa E daigaku yorimo
Univ. $F$ in Univ. $E$ than
ooku-no gakusei-ga syougakukin-wo moratteiru
many-Gen students-Nom FA-Acc receive
b. F daigaku de-wa E daigaku yorimo

\footnotetext{
${ }^{4}$ This analysis is supported by the following examples of proportional readings with mass nouns. Takusan-no allows a proportional reading for mass nouns, but Ooku-no does not.

Kono damu! niwa $\left\{{ }^{*}\right.$ ooku-no/takusan-no $\}$ mizu-ga aru

This dam in much/many water-Nom exist

"There is a lot of water in the dam"

This is because the material described with mass noun cannot be counted. Hence the many $_{2 \mathrm{C}}$ for cardinal reading of ooku-no does not work. This shows that ooku-no cannot provide a proportional reading directly.
} 
Univ. $\mathrm{F}$ in Univ. $\mathrm{E}$ than

takusan-no gakusei-ga syougakukin-wo moratteiru many-Gen students-Nom FA-Acc receive 'More students receive financial aid in Univ. F than in Univ. E.'

These structures and interpretations are represented in (54).

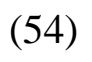

a. *ooku-no ((53a))
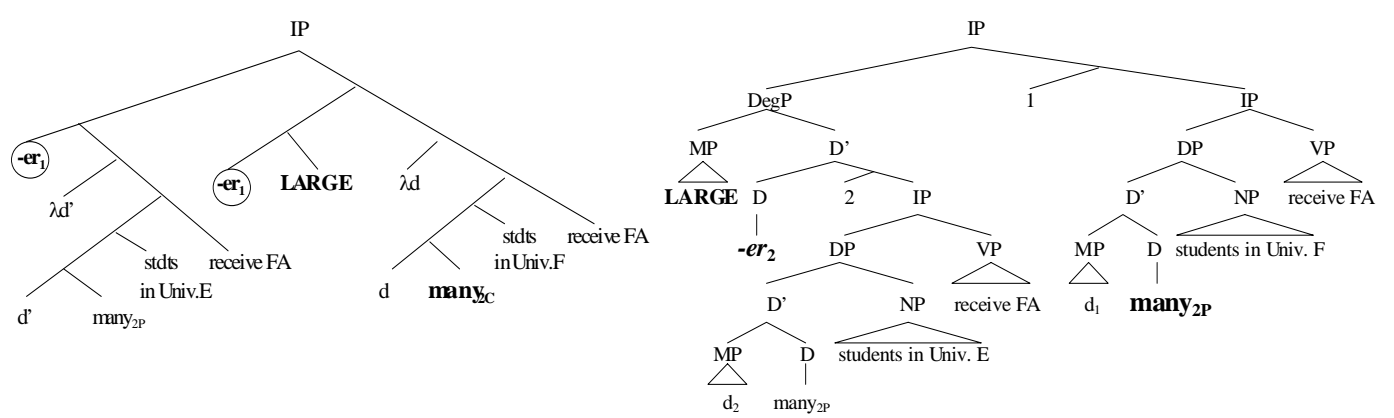

$\llbracket(54 \mathrm{~b}) \rrbracket=1$ iff $\max \left\{\mathrm{d}: \mathrm{d}=\frac{\mid\{\mathrm{x}: \mathrm{x} \text { is a stdt with FA in Univ. } \mathrm{F}\} \mid}{\mid\{\mathrm{x}: \mathrm{x} \text { is a stdt in Univ. } \mathrm{F}\} \mid}\right\}-$ $\max \left\{\mathrm{d}: \mathrm{d}=\frac{\mid\{\mathrm{x}: \mathrm{x} \text { is a stdt with FA in Univ. } \mathrm{E}\} \mid}{\mid\{\mathrm{x}: \mathrm{x} \text { is a stdt in Univ. } \mathrm{E}\} \mid}\right\}=$ "large"

As we have seen in (52a), the proportional reading of ooku-no is given by a comparative construction. Therefore, a proportional comparative requires one more comparative morpheme $-e r_{1}$. In the structure in (54a), the inside $-e r_{1}$ is for the proportional reading, and the outside $-e r_{1}$ is for the comparative. Such 'double standard' for comparatives, however, should be prohibited. This is why ooku-no is not compatible with a proportional comparative reading.

\subsection{Proportional Differential Comparatives}

Finally, let us look at examples of proportional differential comparatives. Neither ooku-no nor takusan-no allow this reading, which was our second question in (19c).

(55) Proportional Differential Comparative under the situation (11)

a. \#F daigaku dewa E daigaku yorimo

Univ. $\mathrm{F}$ in Univ. E than

75\% ooku-no gakusei-ga syougakukin-wo moratteiru

$75 \%$ many-Gen students-Nom FA-Acc receive 


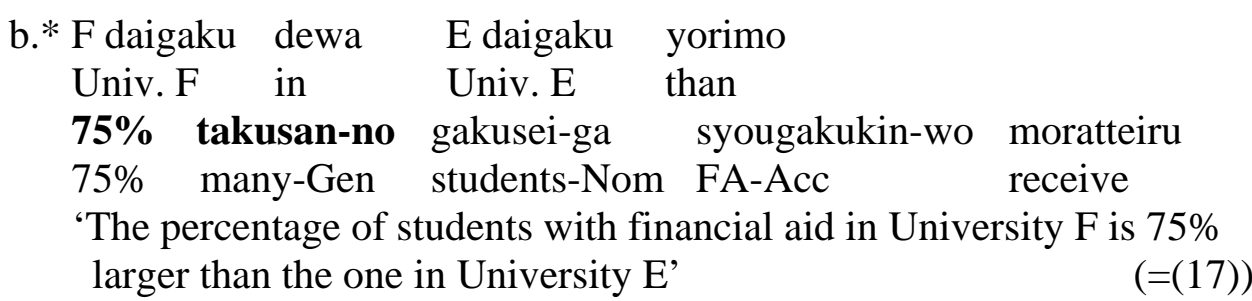

In section 0, we saw that ooku-no does not allow proportional comparative readings because of the double standard prohibition. It means that ooku-no is not compatible with proportional differential comparatives, which is a kind of proportional comparative. As for takusan-no, it does not allow differential comparative readings because of the default degree morpheme $L A R G E$ as we have seen in (50). This is the reason why proportional differential reading not allowed. In (55), the degree morpheme '75\%' and the default degree morpheme LARGE compete the argument status of $-\mathrm{er}_{2}$.

\section{Conclusion}

Japanese ooku-no and takusan-no seem to share the same meaning in noncomparative sentences, but they actually have different meanings in comparative constructions. I suggest that neither of them is the traditional Barwise \& Cooper style determiner many ( $<$ et, $<$ et, $t>>$ type determiner). Both items are lexically decomposed into a number of elements depending on the structure in question. Ooku-no takes cardinal comparative d-many and always shows up in comparative constructions. Takusan-no, on the other hand, must take the 'default' degree morpheme LARGE. The comparative d-many has been suggested for cardinal reading in previous literature. I suggested that there is a proportional d-many as well. Based on this many we can account for the structure and interpretation of proportional comparative sentences with takusan-no in Japanese.

\section{References}

Barwise, Jon and Robin Cooper: 1981, 'Generalized Quantifiers and Natural Language', Linguistics and Philosophy 4, 159-219.

Bresnan, Joan: 1973, 'Syntax of the Comparative Clause Construction in English’, Linguistic Inquiry 4, 275-344.

de Hoop, Helen and Jaume Solà: 1996, 'Determiners, Context Sets, and Focus', Proceedings of the Fourteenth West Coast Conference on Formal Linguistics, CSLI Publications, Stanford, 155-167.

Hackl, Martin: 2000, Comparative Quantifiers. Doctoral Dissertation, MIT.

Heim, Irene: 2000, 'Degree Operators and Scope', in B. Jackson and T. Matthews (eds.) Proceedings of SALT X, CLC Publications, Cornell University, Ithaca, 40-64.

Nakanishi, Kimiko: 2004, Domains of Measurement: Formal Properties of NonSplit/Split Quantifier Constructions. Doctoral Dissertation, University of 
Pennsylvania.

Partee, Barbara H.: 1988, 'Many Quantifiers', Proceedings ESCOL '88, ed. J. Powers and K. de Jong, The Ohio State University, Columbus, 383-402.

Ross, John Robert: 1967, Constraints on Variables in Syntax. Doctoral Dissertation, MIT.

Tanaka, Takuro: 2005, 'Focus, Context, and Many Elements', in E. Maier, C. Bary \& J. Huitink (eds.) Proceedings of Sinn und Bedeutung 9, 461- 474. Radboud University Nijmegen, Holland.

Rullmann, Hotze: 1995, Maximality in the Semantics of Wh-Constructions. Doctoral Dissertation, University of Massachusetts, Amherst.

von Stechow, Arnim: 1984, 'Comparing Semantic Theories of Comparison', Journal of Semantics 3, 1-77. 